\title{
Reconciling the Pro-Choice Argument with the Anti-Life Rhetoric: Issues in the Indian Context
}

\author{
Saloni Dukle*
}

Abstract

The debate concerning the woman's right to choose versus the right to life of the unborn child is centred around the argument, whether one right can be preferred in lieu of another. The law in India simply prohibits abortion unless carried out within twenty weeks, while remaining silent as to the point when life sprouts in the foetus. Further, abortion can only be carried out under specified conditions determined solely by the medical practitioner and not the woman. In this paper, the author argues that prior to foetal viability (twenty-four weeks into the pregnancy, as per studies), the foetus does not classify as a human person and hence, cannot be endowed with the right to life. Thus, the woman's right to choose when and whether to terminate her pregnancy must not be encroached upon by the State, unless absolutely necessary to prevent harm to her life or health. This outlook, tied in with the implications of denying the woman her right to choose, although pro-choice in nature, does not reflect an anti-life sentiment. The author

* Fourth Year, BA LLB (Hons.), The W.B. National University of Juridical Sciences, Kolkata; salonidukle95@gmail.com. 
contends that a pro-choice view does not necessarily impinge upon the foetus's right to life.

Keywords: Abortion, Foetal Viability, MTP Act, Personhood, Right to life.

\section{Introduction}

In earlier times, abortion was viewed as a matter that was influenced by concepts such as Planned Parenthood, regulation of population and the right to property of the patriarch. ${ }^{1}$ Abortion was hardly seen to concern the prospective mother's rights, leave alone the rights of the prospective child. ${ }^{2}$ Abortion can be defined as 'the termination of a pregnancy by the removal or the forcing out of the foetus or the embryo from the womb of the mother'. ${ }^{3}$ Abortion can happen naturally, or can be intentionally caused, the prior being termed as miscarriage and the latter induced abortion. The term abortion is most commonly used and refers to the induced abortion of a human pregnancy. ${ }^{4}$ Unlike in ancient times, the current debate surrounding abortion relates to its moral and legal position, as well as its implications. The two opposing camps in this debate are the 'pro-choice' movement (which stresses upon it being the prospective mother's right to decide whether the pregnancy should be terminated) and the 'pro-life' movement (which emphasizes upon the right of the foetus to be born,

1 JOHN BOSWELL, THE KINDNESSOF STRANGERS: THE ABANDONMENTOF CHILDRENIN WESTERN EUROPEFROM LATE ANTIQUITYTO THE RENAISSANCE (The University of Chicago Press, 1988).

2 Carla Spivack, To"Bring Down the Flowers": The Cultural Context of Abortion Law in Early Modern England, 14 WM.\&MARY J. WOMEN \& L. 107 (2007).

${ }^{3}$ R.M. Youngson, Abortion and Miscarriage in The Royal Society of Medicine Health Encyclopaedia (2000).

${ }^{4}$ Id. 
describing abortion as taking away the life of the foetus, thereby being comparable to murder). ${ }^{5}$

In this paper, the author puts forth the view that, the pro-choice outlook does not necessarily have to be looked at, as being anti-life. While strongly arguing in favour of the prospective mother's right to choose whether or not to terminate her pregnancy, the author first contends that, the woman must be given complete autonomy in deciding the same. While contending so, however, the author ensures that a balance is maintained between the right of the woman to choose and the right to life of the unborn child. This is done by the author by putting forth the argument that while the prospective mother must be given the right to choose, when and whether to terminate her pregnancy, this right must lie with her only up till the point of 'foetal viability', after which it may be curtailed by the State. The author elaborates upon how the foetus can be considered a person having the right to life only upon reaching viability, and hence only then can the woman's right to choose be exercised, subject to the foetus' right to life. It is in this manner, tied in with the implications of denying the woman her right to choose, that the author, puts forth the understanding that upholding the right of the woman to choose to terminate her pregnancy does not necessarily have to mean doing away with the right to life of the foetus, that is, arguing that pro-choice does not necessarily have to mean anti-life.

\section{An Analysis of Existing Legislation and the Woman's Right to Choose}

The statute governing abortion laws in India is the Medical Termination of Pregnancy Act, 1971. This Act, passed in 1971, was formulated to create certain exceptions to the stringent provisions governing abortion under the Indian Penal Code, 1860, which asserted that all abortions constituted crimes, unless carried out in order to save the life of the prospective mother. ${ }^{6}$

5 Tom Head, Pro-Life vs. Pro-Choice, ABOUT NEWS, (last updated July 31, 2015), available at http://civilliberty.about.com/od/abortion/tp/ProLife-vs-Pro-Choice.htm.

${ }^{6}$ INDIAN PENAL CODE, 1860 § 312. 
The Medical Termination of Pregnancy Act, 1971 (hereinafter referred to as 'MTP Act') allows the termination of a pregnancy under Section 3, solely on three definite grounds: firstly, as a way to protect the life of the prospective mother, on there being a cognizable danger to her mental or physical health; secondly, on grounds of humanity wherein the pregnancy has taken place owing to a crime such as rape, intercourse with a lunatic woman etc.; and lastly, where there exists a clear risk of the child being born with severe abnormalities or deformities. ${ }^{7}$ It is however, not sufficient that the woman fulfils these conditions by providing proof pertaining to one of the above, but the decision to abort must have been taken exclusively by the medical practitioner in whose care the woman lies. ${ }^{8}$ The Act, therefore, not only restricts the ambit of rights available to a woman, with regard to facilitating an abortion, but also necessitates its undertaking by a registered medical practitioner, who has to decide the same on the basis of "good faith", which has not been defined under the Act. ${ }^{9}$ The author argues that it is vital that the woman be granted complete power to make decisions pertaining to her own body, in order to protect her decisional autonomy under the Act.

The view to provide a woman with this right flows from her constitutional guarantee of the right to her life and personal liberty, which includes the right to her bodily privacy. In India, the right to life and personal liberty has been recognized under Article 21 of the Constitution which states that "No person shall be deprived of his life and personal liberty except according to procedure established by law." $10^{\prime}$ Person' here includes both man and woman. Hence, among the various rights that are available to a woman under Article 21, the right to abortion is essential. The MTP Act, 1971 however, evidently does not incorporate a fundamental right to induced abortion, instead legalizing thecircumstances under which women may have access to abortion services. The termination of a

\footnotetext{
7 The Medical Termination of Pregnancy Act, 1971, § 3 .

8 The Medical Termination of Pregnancy Act, 1971, § 5 .

${ }^{9}$ The Medical Termination of Pregnancy Act, 1971, § 3 .

10 THE CONSTITUTION OF INDIA, Art. 21.
} 
pregnancy under the MTP Act, 1971 can thus be labeled as a 'therapeutic' intervention rather than a right. ${ }^{11}$

Another critique of the MTP Act, 1971 affecting this right, is the fact that the clause permitting an abortion in case of a contraceptive failure, applies only to married women. ${ }^{12}$ The author is of the opinion that this discrepancy in providing safe abortion care to married women, while ignoring the needs of unmarried women, requires immediate revision in light of the changing dynamics of social construct as it violates the provisions under Article 21 of the Constitution.

The right to bodily privacy and integrity, as emanating from the constitutionally guaranteed right to life and personal liberty must be seen to include two fundamental components: namely the right of a person to be able to choose how to live her own life, and the right of the person to assent to the effects on her privacy and bodily integrity. Hence, not only must a woman be given the right over her body, but also the right to consent to what can be done to it; the latter being a right far more important in nature than the former. ${ }^{13}$ If a balance needs to be maintained between the right to life of a woman and that of the foetus, such a balance should be worked to the point when the foetus can be said to, have such a right. The author puts forth the view that the State must not encroach upon the right of the woman to autonomously determine whether or not to terminate her pregnancy, until the point where the foetus can be said to, in actuality, have such a right. This right of the prospective mother can be curtailed only in cases where the decision to abort is harmful to the health and life of the prospective mother.

${ }_{11}$ Amar Jesani \& Aditilyer, Abortion:Who is responsible for our rights?, CENTRE FOR ENQUIRY INTO HEALTH AND ALLIED THEMES, available at http://www.cehat.org/publications/pc06a40.html.

12 The Medical Termination of Pregnancy Act, 1971, § 3 Exp. 2.

${ }_{13}$ Eileen L. McDonagh, My Body, My Consent: Securing the Constitutional Right to Abortion Funding, 62(3) ALBANY LAW REV. 1057 (1999). 


\section{Personhood and Foetal Viability}

The development of the foetus into a 'person' has been a topic of debate as there are differences in opinion as to how 'personhood' may be defined, and also with respect to the nature of that status. The idea of personhood was traditionally viewed to involve the concept of a soul, which denoted a non-corporeal dimension to a human being. ${ }^{14}$ Over time, however, this notion has undergone some change, with a number of other aspects being used to determine the same. The concept of personhood, is now seen to be intrinsically linked with the concept of foetal viability, which is used as a measure to establish whether a foetus has developed into a human 'person'. Viability of the foetus refers to the potential of the foetus to survive outside the uterus after birth, natural or induced, ${ }^{15}$ which depends, to a large extent, upon the maturity of the foetus and the development it has undergone, inside the mother's womb. It is argued that, a foetus can be classified as a human person only when it is capable of such survival outside the mother's womb, prior to which it is dependent on the mother for survival and hence, should not be endowed with rights. A distinction must be drawn between a human being and a human person. While a foetus may be biologically human, having the potential to develop into a human person, it does not still classify as a human person who should be given the right to life. Thus, whether abortion is against the interest of a foetus must depend on whether the foetus itself has interests, and not on whether the interests will develop, if no abortion takes place. ${ }^{16}$ It is argued that, once a foetus is able to live on its own it may have interests, and this should be held as the point of foetal viability.

14 CHARLES TAYLOR, SOURCES OF THE SELF: THE MAKINGOF THE MODERN IDENTITY (Cambridge University Press 2nd ed. 1992).

15 Sheryl Gay Stolberg, Senate tries to define Fetal Viability, N. Y. TIMES,(May 16, 1997), available athttp:/ / www.nytimes.com/1997/05/16/us/ senate-tries-to-define-fetalviability.html.

16 JONATHAN HERRING, MEDICAL LAWAND ETHICS(Oxford University Press, 2nd ed. 2008). 
The concept of foetal viability and the important role played by it in determining whether a foetus should have the right to life was brought to fore by two important U.S. cases; namely Roe v. Wade17 and Planned Parenthood v. Casey ${ }^{18}$. Roe v. Wade kindled a universal debate as to whether, and to what extent, abortion should be made legal. It was laid down by this case that, the right of a woman to choose whether or not to have an abortion emanates from her right to privacy, and that this right must be balanced in favour of certain fundamental state interests; viz., protecting the health of the prospective mother and prenatal life. These interests of the State, were said to become stronger over the course of the pregnancy, and State regulation is applicable to the third trimester, that is, when the foetus is said to be viable. The case defined 'viable' as being 'potentially able to live outside the mother's womb, albeit with artificial aid', with the addition that, viability 'is usually placed at about seven months (twenty-eight weeks) but may occur earlier, even at twenty-four weeks.' ${ }^{19}$ This decision of the Court was modified to a certain extent in the case of Planned Parenthood $v$. Casey, wherein the Court rejected Roe v. Wade trimester framework, holding that during the first trimester of pregnancy, there should not be any interference by the State. The decision to abort must be left with the pregnant woman, because early in the pregnancy, abortion is safe, with mortality being less than the mortality of normal child birth. In the second trimester of the pregnancy and until the point of viability, abortion may be regulated by the State, only when the regulation is needed to preserve maternal health. In the third trimester of the pregnancy, when foetal viability comes into question, the State can curb the right of the mother to abort her pregnancy. The State can do so in order to fulfil its compelling interests, although such regulation cannot be done at the cost of the mother's health there by allowing the prospective mothers' right to abortion until viability, without 'undue burdens' 20 being placed on them up to the point of viability.

\footnotetext{
17 Roe v. Wade, 410 U.S. 113 (1973).

18 Planned Parenthood v. Casey, 505 U.S. 833 (1992).

19 Roe v. Wade, 410 U.S. 113 (1973).

20 'Undue burden' is defined as the effect upon a woman resulting out of placing substantial obstacles in the path of woman so as to curb her right
} 
USA and UK recognise two important components in determining where to draw the line with respect to abortion. ${ }^{21}$ The primary factor is foetal viability or the viability of the foetus' independent existence outside the womb. ${ }^{22}$ The viability period is fixed at twenty-four weeks which can also be assumed as the age, the foetus attains personhood. ${ }^{23}$ This is in actuality a rather conservative estimate, as only a very small number of babies born at twenty-four weeks gestation can survive. ${ }^{24} \mathrm{~A}$ study conducted showed that babies born at around this period had a $26 \%$ expectancy of reaching age six and of those that did, more than $50 \%$ suffered moderate or severe disability. ${ }^{25}$ There are also those who argue that abortion restrictions must account for the ability of the foetus to experience the sensation of pain. Medical evidence with regard to this tells us that the foetus is actually unconscious for the first thirty weeks and is not likely to experience pain until the third trimester. ${ }^{26}$ Hence, a combination of the viability test and the above evidence would suggest that abortion limits should at least be fixed at twenty-four weeks, if not higher.

The second component is the other stakeholder's interests i.e. the woman. It is often argued that, the abortion limit must be kept low so as to ensure the least possible harm being caused to the woman

in exercising her choice with respect to whether or not to have an abortion.

21 Bonnie Hope Arzuaga \& Ben Hokew Lee, Pediatrics Perspective; Limits of Human Viability in the United States: A Medicolegal Review Pediatrics, 128(6) OFFICIAL JOURNALOF THE AMERICAN ACADEMYOF PEDIATRICS 1047

available athttp:/ / pediatrics.aappublications.org/content/128/6/1047.full.

22 Stolberg, supra note 15.

23 Marco Narajos, Should the Legal Abortion Limit of 24 Weeks Be Changed?, The MedSchool Project, (Sept. 2, 2011), available at http:/ / www.themedschoolproject.com/2011/08/should-legal-abortionlimit-of-24-weeks.html.

24 Science and Technology Committee, House of Commons, Great Britain, Scientific Developments Relating to the Abortion Act 1967: Twelfth Report of Session 2006-07.

25 Id.

${ }^{26}$ Narajos, supranote 24. 
during the process; the harm caused, is considered to be far higher as the pregnancy progresses. ${ }^{27}$ Studies, however, show that the chance of death of the woman is now only about 1 in every 100,000 at twenty-four weeks, ${ }^{28}$ and cases of injury are rare as well, with only $0.1 \%$ of cases reporting an injury related to the procedure. Thus, the medical technology available now is certainly sufficient to rule out harm to the woman as a cause for concern.

In India, the MTP Act, 1971 legalises abortion up to twenty weeks. Based on the logic of the viability test and the harm-to-woman principle, as well as the immense advancement of technology since the enactment of the statute, this provision is clearly out-dated and must be revised to the more internationally concomitant standard of twenty-four weeks. ${ }^{29}$ In fact, the chance of viability at twentyfour weeks is a conservative one even in the more technologically developed West. ${ }^{30}$ Moreover, the abortion procedures in India do not pose a higher risk to the woman at week twenty-four than at twenty. ${ }^{31}$ The issue in India has gained a significantly larger amount of traction after the Niketa Mehta case 32 where abortion was denied even though the congenital heart problem in question could only be identified in the twenty-fourth week. Several diagnostic tests, determining the presence of severe abnormalities, disabilities etc., can be carried out only post the twentieth week of pregnancy, thereby crossing the prescribed abortion limit as under the MTP Act. ${ }^{33}$ The author therefore, argues that certain provisions of the MTP Act need revision so as to ensure that the prospective mother

27 Id.

${ }^{28} I d$.

29 MeenakshiUpreti\& Nikita Mishra, Centre to Amend Abortion Law, to Allow Pregnancy Termination till 24 Weeks, IBN LIVE, (Nov. 6, 2014) available to http://ibnlive.in.com/news/centre-to-amend-abortion-lawto-allow-pregnancy-termination-till-24-weeks/511065-17.html.

30 Indo Asian News Service,Gynaecologists Support Niketa Mehta on Abortion, INDIA TODAY (Aug. 7, 2008), available at http://indiatoday.intoday.in/story/Gynaecologists+support+Niketa+Me hta+on+abortion/1/12668.html.

${ }^{31} \mathrm{Id}$.

${ }^{32} \mathrm{Id}$.

${ }^{33} \mathrm{Id}$ 
is not deprived of her right to choose whether and when to terminate her pregnancy till the point of foetal viability, as it is only then that the foetus can be called a human person.

\section{Implications of Denying a Woman Her Right to Choose}

It is argued by the author that, by not giving a woman the right to choose to terminate her pregnancy prior to viability, without the interference by a medical practitioner, may result in an increase in women opting for illegal abortions. A large number of illegal abortions are carried out, which are immensely unsafe for women and lead to an increase in maternal mortality owing to the absence of professional abortion facilities. As per a study carried out by the World Health Organisation and the Guttmacher Institute on a global level, abortions are the most unsafe when carried out illegally. ${ }^{34}$

Denying a woman the absolute right to abortion, prior to foetal viability, can also be viewed as a practice of female oppression under a system of patriarchy, which exists in India. Margaret Sanger, founder of the Planned Parenthood Federation of America wrote: "No woman can call herself free until she can choose consciously whether she will or will not be a mother" 35 This is owing to the rationale that during pregnancy, the prospective mother would be burdened with a responsibility she may be unable or unwilling to take up, if not autonomously allowed to terminate her pregnancy before viability; a responsibility that a potential father is not loaded with.

It is often the opinion of supporters of the pro-life movement that in allowing the prospective mother complete autonomy in deciding whether to terminate her pregnancy before viability, the result will be an increase in sex-selective abortion. Sex-selective abortion refers to the practice of terminating a pregnancy based upon the predicted sex of an infant and aborting the foetus if it is found to be

34 Elizabeth Rosenthal, Legal or Not, Abortion Rates Compare, N. Y. TIMES (Oct. 12, 2007), available at http://www.nytimes.com/2007/10/12/world/12abortion.html?_r=1\&.

35 Arguments in Favour of Abortion, BBC, available at http://www.bbc.co.uk/ethics/abortion/mother/for_1.shtml\#h4. 
of the unwanted sex, ${ }^{36}$ usually female. This view is strengthened by the fact that such a practice is already rampant in India. The author, however, thinks it important to point out that the Pre-Conception and Pre-Natal Diagnostic Techniques Act, 1994 (hereinafter referred to as the 'PCPNDT Act') was enacted by the Indian Parliament so as to deter and punish prenatal sex screening and sex selective abortions. The Act provides for the prohibition of sex selection and regulates the use of pre-natal diagnostic techniques, by restricting their use to detecting certain abnormalities and disorders, as have been provided for under the Act. ${ }^{37}$ The Act prohibits medical centres from conducting tests to determine the sex of the foetus ${ }^{38}$ and even when permitted to conduct diagnostic tests, precludes any person from communicating the foetus' sex to the pregnant woman or her family. ${ }^{39}$ The author argues that, the practice of sex-selective abortion can take place illegally irrespective of whether the woman is given such decisional autonomy, prior to viability. What is needed instead, according to the author, is a strict adherence to the PCPNDT Act, with stringent measures taken by the law to ensure the same, rather than curbing this right of the woman. Since there already is a mechanism in place to prevent sex-selective abortions, the State must aim to ensure better implementation of the same, rather than depriving the prospective mother from exercising her right to choose whether or not to terminate her pregnancy prior to viability.

\section{Conclusion}

The central issue in this context comes down to the right of the woman to choose to abort and how it conflicts with the obligation of the State to preserve life. Legally speaking, the question as to when the foetus becomes a 'person' is still highly ambiguous and the MTP Act prohibits abortion except under the stipulated conditions. While the law declares that, abortion is illegal after twenty weeks of pregnancy; studies show that, the foetus does not

\section{${ }^{36} I d$.}

37 ThePre-Conception and Pre-Natal Diagnostic Techniques Act, 1994 § 4.

38 ThePre-Conception and Pre-Natal Diagnostic Techniques Act, $1994 \S 6$.

39 ThePre-Conception and Pre-Natal Diagnostic Techniques Act, $1994 \S 5$. 
become a person even after twenty-four weeks of pregnancy. Thus, the question of when the State should encroach upon the woman's right to abortion is rekindled, especially in cases where the health or life of the woman is at risk. It is therefore contended that, until the foetus becomes viable, that is, becomes a 'person' in the legal sense, a pro-choice view of the abortion debate does not necessarily imply being anti-life in actuality. 